\title{
Upstream Horizontal Mergers, Vertical Contracts, and Bargaining
}

\author{
Chrysovalantou Milliou and Emmanuel Petrakis*
}

\author{
March 2006
}

\begin{abstract}
We study horizontal mergers in the upstream sector of a vertically related industry in which firms bargain over their contract terms. We demonstrate that the contract type is crucial for the merger incentives and the merger effects. When trading takes place through two-part tariff contracts, and not through wholesale price contracts, upstream firms have no incentives to merge. When the contract type is endogenous and the upstream bargaining power is sufficiently low, merger incentives are present and wholesale price contracts are chosen in equilibrium. Finally, upstream horizontal mergers can be procompetitive even in the absence of efficiency gains.
\end{abstract}

JEL Classification: L41; L42; L22

Keywords: horizontal mergers; bargaining; vertical relations; two-part tariffs; wholesale prices; merger policy

*Milliou: Department of Economics, Universidad Carlos III de Madrid, Getafe (Madrid) 28903, Spain, e-mail: cmilliou@eco.uc3m.es; Petrakis: Department of Economics, University of Crete, Rethymnon 74100, Greece, email: petrakis@ermis.soc.uoc.gr. We are greatful to Lluis Bru, Ramon Fauli-Oller, Esther Gal-Or, Marc Möller, Carlos Ponce, and Nikolaos Vettas for useful suggestions. We would like to thank participants at CRETE 2005 at Syros, EARIE 2005 at Porto, XX Jornadas de Economia Industrial at Bilbao, ASSET 2005 at Rethymnon, and WZB seminar series at Berlin for their comments. Full responsibility for all shortcomings is ours. 


\section{Introduction}

Many of the mergers that come before the antitrust agencies involve firms that produce intermediate goods such as the recent mergers between car engine suppliers (Kolbenschmidt/Pierburg), medical device providers (General Electrics/Instrumentarium), or health IT suppliers (iSoft/ Torex). Clearly, the parties involved in these mergers sell in turn their products to firms that produce final goods, that is, they deal with firms that operate closer to the final consumers. It follows then that although these mergers are horizontal, they take place in vertically related industries.

An important feature of vertically related industries is that the terms of trade between the upstream and the downstream firms are often determined through bargaining. For example, large food retailers as well as general retailers (e.g. Wal-Mart) bargain over the terms of trade with their suppliers, car manufacturers bargain with car parts providers, and large book retailers (e.g. Barnes \& Noble) bargain with publishers. ${ }^{1}$ A second important feature of vertically related industries is that the trading between the vertically related firms can take many different forms. While for instance in some industries firms trade using simple linear contracts, in others, they trade using more complicated contract types.

The objective of this paper is to explore the role of both the presence of bargaining and of the type of contracts employed for the incentives and the welfare effects of upstream horizontal mergers, that is, of horizontal mergers that take place in the upstream sectors of vertically related industries. To fullfil this objective, we consider an industry with two vertical chains, each consisting of an upstream and a downstream firm that bargain over their contract terms and trade either through a standard linear wholesale price contract or through a nonlinear contract that takes the form of a two-part tariff. The timing of moves is as follows. In stage one, the upstream firms decide whether or not to merge horizontally. In the following stage, they choose their contract types, that is, they decide whether they will trade using wholesale price or two-part tariff contracts. If the merger has taken place, then in stage three, the newly formed upstream monopolist bargains simultaneously and privately with the two downstream firms over their contract terms. If instead the firms have remained separated, each separate upstream firm bargains only with its respective downstream customer. Finally, in stage four,

\footnotetext{
${ }^{1}$ See e.g. "Barnes \& Noble to Try to Squeeze Better Publisher Deals", The New York Times, November 26, 2001, and "How Big Can it Grow", The Economist, April 15, 2004.
} 
the downstream firms compete in quantities.

A key difference between a merged upstream firm and an independent upstream firm stems from the fact that an increase in the wholesale price charged to one downstream firm leads to an increase in the rival downstream firm's output. The latter effect is negative for the upstream firms under two-part tariffs and positive under wholesale price contracts simply because only in the former case downstream production is subsidized (i.e. wholesale prices are below the upstream marginal cost). A merged supplier, in contrast to an independent one, sells to both downstream firms and thus internalizes this negative (positive) effect under two-part tariffs (wholesale prices). The internalization of this effect in the merger case leads to a decrease in the wholesale prices under two-part tariff contracts and to an increase under wholesale price contracts. The lower (higher) wholesale price contracts under two-part tariffs (wholesale prices) lead in turn to stronger (weaker) downstream competition and thus to a smaller (larger) total surplus in the case of merger than in the case that firms remain separated.

A second key difference between a merged upstream firm and an independent upstream firm is that, only the former's disagreement payoff is not zero. This is so because when the merged upstream firm disagrees with one of the downstream firms, it still has the option of reaching an agreement with the rival downstream firm. One might expect that this would imply that the merger enhances the upstream bargaining position and thus increases the upstream share of the total surplus. And indeed this is so when firms trade using linear wholesale price contracts. Surprisingly though, when firms trade using two-part tariff contracts, the mere existence of an outside option can weaken the upstream bargaining position. This is so because in case of disagreement with one of the downstream firms, the production of the rival downstream firm that acts as a monopolist in the final product market is subsidized under two-part tariff contracts. In other words, the variable part of the merged firm's disagreement payoff is negative. The fixed part of the disagreement payoff does not always offset its negative variable part, and as a consequence the total disagreement payoff of a merged firm is either negative or small.

When trading takes place through two-part tariff contracts, then in accordance with our above discussion, an upstream horizontal merger leads, first, to a smaller total surplus, and second, to either a small increase or to a decrease $n$ the upstream share of the surplus. Given this, the upstream firms prefer to remain separated. Exactly the opposite holds when trading takes place through wholesale price contracts since the merger has then a positive impact both 
on the wholesale prices and on the upstream bargaining position.

While separate upstream firms always choose to trade using two-part tariff contracts, a merged upstream firm chooses to trade with two-part tariff contracts when its bargaining power is sufficiently high and the final products are not very close substitutes and with wholesale price contracts otherwise. This occurs for the following reasons. First, as mentioned above, under two-part tariff contracts, the wholesale prices are lower, and thus, the downstream competition is stronger and the total surplus is smaller than under wholesale price contracts. When the goods are close substitutes, and thus downstream competition is already quite fierce, the total surplus under two-part tariff contracts gets even smaller than the respective one under wholesale price contracts and the merged firm's disincentives to use two-part tariff contracts are reinforced. Second, while under two-part tariffs, the merged firm receives the share of the joint surplus that corresponds to its bargaining power, under wholesale price contracts it receives a lower portion of the surplus. When the upstream bargaining power is high, the merged firm cannot take the full advatage of its high bargaining power under wholesale contracts, and thus, its incentives to use such contracts are quite low. Combining our findings regarding the endogenous contract types, with the above mentioned absence of merger incentives under twopart tariff contracts, it follows that a merger does not take place in the presence of powerful upstream firms. When instead the upstream firms do not hold a lot of bargaining power, an upstream horizontal merger can arise in equilibrium because then the merged firm chooses to trade through wholesale price contracts.

Regarding the welfare effects of upstream horizontal mergers, we show that such mergers can be procompetitive even if they do not generate any synergies. In particular, when bargaining takes place over two-part tariff contracts, an upstream merger is beneficial both for consumers and overall welfare. The impact of the merger on consumers' surplus is clearly due to the lower wholesale prices which lead to lower final good prices. Surprisingly, the downstream firms are also better off when the upstream merger takes place. This is so because when the downstream firms deal with an upstream monopolist, they face better terms of trade. The two positive effects of a merger, on consumer surplus and downstream profits, dominate its negative effect on upstream profits, and the upstream merger turns out to be welfare improving when two-part tariff contracts are used. A reversal of all the above results occurs when wholesale contracts are used since the intuitive arguments work in exactly the opposite direction.

Our findings have important implications for merger policy. The merger regulation (see e.g. 
U.S. Merger Guidelines) fails to distinguish among horizontal mergers under different vertical trading arrangements. Our findings highlight the role of vertical trading arrangements on the welfare impact of horizontal mergers. Hence, they clearly suggest that the antitrust authorities should take the trading arrangements into account in their treatment of horizontal mergers in intermediate industries.

The literature on horizontal mergers is quite extensive. However, most of this literature has focused on mergers that take place in industries that include only one production stage, and in particular, on mergers among firms that sell directly to consumers. That is, it has, to a great extent, ignored horizontal mergers that take place among firms that operate in vertically related industries. The seminal paper of Horn and Wolinsky (1988) is one of the few exceptions. Under the same market structure as ours, Horn and Wolinsky (1988) show that when the downstream firms' products are substitutes, the upstream firms always have incentives to merge as the merger allows them to charge higher wholesale prices. However, Horn and Wolinsky obtain this result under the assumption that firms bargain only over linear wholesale price contracts, that is, they restrict attention to only one contract type. We instead explore the role of contract types for merger incentives by allowing for a more general contract space as well as by endogenizing the contract type. Doing so, we demonstrate their result is quite sensitive to the type of contract used, but more importantly, we highlight the significance of the contract type in the analysis of mergers in intermediate product industries.

Ziss (1995) also explores the incentives for upstream horizontal mergers. Restricting attention to only two-part tariff contracts, he finds that a merger is welfare decreasing and that, merger incentives are always present. ${ }^{2}$ Although Ziss (1995) considers the same market structure with us and Horn and Wolinsky (1988), he abstracts from the possibility of bargaining and assumes that in the merger case the upstream monopolist chooses the contract terms with its downstream customers unilaterally and publicly. We demonstrate that his results are extremely sensitive to this assumption.

In a model in which firms trade using only two-part tariff contracts, Ziss (1995) confirms the

\footnotetext{
${ }^{2}$ O'Brien and Shaffer (2005) and Inderst and Wey (2003) also examine upstream horizontal mergers. However, they consider settings which are very different from ours (e.g. settings without downstream competition). von Ungern-Sternberg (1996), Dobson and Waterson (1997), Lommerud et al. (2005), and Symeonides (2005) examine instead horizontal mergers in the downstream sector of vertically related industries. With the exception of Symeonides (2005), they all restrict attention to wholesale price contracts. None of these papers explores the role of vertical contracts for merger incentives.
} 
above mentioned result of Horn and Wolinsky (1988) and shows that an upstream horizontal merger is welfare detrimental. In contrast to us and to Horn and Wolinsky (1988), Ziss abstracts from the possibility of bargaining by assuming that the upstream firms unilaterally and irrevocably set the terms of contracts. As we demonstrate, his results are extremely sensitive to the presence of bargaining. ${ }^{3}$

The remainder of the paper is organized as follows. In Section 2, we describe our model. In Section 3, we characterize the equilibrium in the output and the bargaining stage. In Sections 4 and 5 respectively, we examine the upstream firms' incentives to merge in the case of exogenous and endogenous contracts. In Section 6, we evaluate the welfare implications of an upstream horizontal merger. In Section 7, we check the robustness of our results under sequential bargaining. Finally, in Section 8, we conclude. The proofs that are not included in the main text are relegated to Appendix B.

\section{The Model}

\section{Market Structure and Contract Types}

We consider a two-tier industry consisting of two upstream and two downstream firms, denoted respectively by $U_{i}$ and $D_{i}$, with $i=1,2$. One could think of the upstream and the downstream firms as being respectively input producers and final good manufacturers, labor unions and firms, wholesalers and retailers. There is a one-to-one relation between the products of the upstream and the downstream firms and an exclusive relation between $U_{i}$ and $D_{i}{ }^{4}$ This could be the case, for instance, because the products of the upstream suppliers are specifically designed for a particular downstream firm, e.g. the input produced by $U_{i}$ has value only for $D_{i} \cdot{ }^{5}$

\footnotetext{
${ }^{3}$ O'Brien and Shaffer (2005) and Inderst and Wey (2003) also examine upstream horizontal mergers. However, they consider settings which are very different from ours (e.g. settings without downstream competition). von Ungern-Sternberg (1996), Dobson and Waterson (1997), Lommerud et al. (2005), and Symeonides (2005) examine instead horizontal mergers in the downstream sector of vertically related industries. With the exception of Symeonides (2005), they all restrict attention to wholesale price contracts. None of these papers explores the role of vertical contracts for merger incentives.

${ }^{4}$ Exclusive buyer-supplier relations are observed in many industries. For instance, car equipment suppliers are very often bond to car manufacturers with exclusive dealing contracts, gasoline retailers hold exclusive relations with petroleum firms, etc.

${ }^{5}$ This could also be the case because of sunk investments such as irreversible R\&D investments that create "lock-in" effects and/or very high switching costs. For a further justification of this assumption see e.g. Horn and Wolinsky (1988), Gal-Or (1991), and Lommerud et al. (2005).
} 
The inverse demand function faced by a downstream firm $D_{i}$ is:

$$
p_{i}=a-q_{i}-\gamma q_{j}, \quad i, j=1,2, \quad i \neq j, \quad 0<\gamma<1
$$

where $p_{i}$ and $q_{i}$ are respectively $D_{i}$ 's price and output, and $q_{j}$ is $D_{j}$ 's output. The parameter $\gamma$ denotes the degree of product substitutability. Namely, the higher is $\gamma$, the closer substitutes the products of $D_{i}$ and $D_{j}$ are.

Each upstream firm faces a constant marginal cost of production $c$, with $0 \leq c<a$, while each downstream firm faces no other cost than the cost of obtaining the input from its upstream supplier. The latter consists of a per-unit of input price $w_{i}$ when trading is conducted through a linear wholesale price contract, and of both a wholesale price $w_{i}$ and a fixed fee $F_{i}$ when trading is instead conducted through a non-linear two-part tariff contract.

\section{- Sequence of Events and Bargaining Framework}

Firms play a four-stage game with observable actions. In stage one, the upstream firms decide whether or not to merge horizontally. If the upstream firms merge, they form an upstream monopolist denoted by $U$. In stage two, the upstream firms - merged or separated - choose their contract types, that is, they decide whether they will trade using wholesale price or two-part tariff contracts. If the upstream firms have remained separated, then in stage three, each downstream firm $D_{i}$ bargains with its upstream supplier $U_{i}$ over their contract terms. If instead the upstream firms have merged, then in stage three, the newly formed upstream monopolist $U$ bargains with the two downstream firms over their contract terms. In the final stage, stage four, the downstream firms compete in the final market in quantities.

We model the negotiations that take place in the third stage of the game as a generalized Nash bargaining problem, where the bargaining power of each upstream and downstream firm is respectively $\beta$ and $1-\beta$, with $0<\beta \leq 1$. We assume that during the negotiations, each bargaining unit takes as given the outcome of the negotiations in the other unit, that is, the solution concept employed is the Nash equilibrium between the two Nash bargaining problems.

In the case that the upstream horizontal merger takes place, we assume that the upstream monopolist bargains with the two competing downstream firms simultaneously and separately/privately. ${ }^{6}$ This is a standard assumption in situations with multilateral contract-

\footnotetext{
$D_{2}$.

${ }^{6}$ In Section 7, we consider the case in which $U$ bargains sequentially instead of simultaneouly with $D_{1}$ and
} 
ing (see e.g. Cremer and Riordan, 1987, Horn and Wolinsky, 1988, Hart and Tirole, 1990, O'Brien and Shaffer, 1992, McAfee and Schwartz, 1994, Marshall and Merlo, 2004). The rationale for the separate negotiations could simply be that the upstream monopolist has two different representatives, each of them negotiating with a different downstream firm. ${ }^{7}$ As it has been noted by the literature, in settings with private contracting, multiple equilibria can arise due to the multiplicity of the beliefs that the downstream firms can form when they receive out-of-equilibrium offers. ${ }^{8}$ Following Horn and Wolinsky (1988) as well as Cremer and Riordan (1987), and O' Brien and Shaffer (1992), we obtain a unique equilibrium by imposing pairwise proofness on the equilibrium contracts. A contract between $U$ and $D_{i}$ is pairwise proof, if there are no incentives for a bilateral deviation of $U$ with the rival downstream firm $D_{j}$, holding the contract with $D_{i}$ constant. $^{9}$

In order to avoid possible non-existence problems of a pairwise proof equilibrium, and in particular, in order to guarantee that profits are non-negative in all the cases under consideration, we assume the following throughout the paper: ${ }^{10}$

Assumption 1: $\beta>\bar{\beta}(\gamma)=\gamma^{3} /\left(4-2 \gamma(1+\gamma)+\gamma^{3}\right)$.

\section{Downstream Competition and Bargaining Outcomes}

In the downstream competition stage, independently of whether or not the upstream merger has taken place as well as independently of the contract type used, each $D_{i}$ chooses its quantity $q_{i}$, taking $q_{j}$ as given, in order to maximize its (gross) profits:

$$
\max _{q_{i}} \pi_{D_{i}}\left(q_{i}, q_{j}, w_{i}\right)=\left(a-q_{i}-\gamma q_{j}\right) q_{i}-w_{i} q_{i} .
$$

\footnotetext{
${ }^{7}$ Two additional justifications for why the negotiations with the two downstream firm take place privately/separately and not in the same room are, first, the fact that making one contract contingent on other contracts may be quite complex, and second, that third parties may be unable to observe others' dealings and verify them to court (see McAfee and Schwartz, 1995).

${ }^{8}$ For additional information see McAfee and Schwartz (1995).

${ }^{9}$ Pairwise proofness is very close in spirit to the passive beliefs assumption used by Hart and Tirole (1990) and McAfee and Schwartz (1994). Under passive beliefs, when a downstream firm receives an unanticipated contract offer, it believes that the upstream monopolist does not alter the contract offer that it makes to the rival downstream firm. Note though that passive beliefs are more restrictive than pairwise proofness since in the former you have to check not only for bilateral, but also for multilateral deviations.

${ }^{10}$ McAfee and Schwartz (1995) have demonstated that such an assumption is necessary for the existence of a pairwise proof equilibrium. It is important to note that we would have obtained the same equilibrium outcomes with passive beliefs under a more strict condition, i.e. when $\beta>\frac{\gamma\left(4-\gamma^{2}\right)}{2\left(2-\gamma^{2}\right)}>\bar{\beta}(\gamma)$.
} 
The first order conditions give rise to the following reaction functions:

$$
R_{i}\left(q_{j}, w_{i}\right)=\frac{a-w_{i}-\gamma q_{j}}{2}
$$

Clearly, a decrease in the wholesale price faced by $D_{i}$ shifts its reaction function upwards and turns $D_{i}$ into a more aggressive downstream competitor.

Solving the system of reaction functions (3), we obtain the equilibrium quantities for given levels of input prices:

$$
q_{i}\left(w_{i}, w_{j}\right)=\frac{a(2-\gamma)-2 w_{i}+\gamma w_{j}}{4-\gamma^{2}} .
$$

In the previous stage, stage three, firms bargain over the contract terms. Because the bargaining game in the case of merger differs significantly from that in the case of separate firms, in what follows we analyze the two cases separately.

\section{- Separate Upstream Suppliers}

When the upstream firms remain separated, there are two vertical chains in the industry and two available contract types. Thus, there are four possible third-stage subgames to consider. Given that the analysis for the subgame in which both chains bargain over wholesale price contracts can be found in Horn and Wolinsky (1988), we simply summarize it in Appendix A, and we analyze here in detail only the remaining subgames.

\section{Bargaining over Two-part Tariff Contracts}

We start with the subgame in which both vertical chains trade using two-part tariff contracts, and thus, the upstream and the downstream firms bargain over both wholesale prices and fixed fees.

When $U_{i}$ and $D_{i}$ bargain over $w_{i}$ and $F_{i}$, they take as given the outcome of the simultaneously run two-part tariff negotiations between $U_{j}$ and $D_{j}$. In particular, letting $\left(w_{j}^{S T}, F_{j}^{S T}\right)$ denote the equilibrium outcome of the bargaining between $U_{j}$ and $D_{j}, w_{i}$ and $F_{i}$ are chosen in order to maximize the generalized Nash product:

$$
\max _{w_{i}, F_{i}}\left[\pi_{U_{i}}\left(w_{i}, w_{j}^{S T}\right)+F_{i}\right]^{\beta}\left[\pi_{D_{i}}\left(w_{i}, w_{j}^{S T}\right)-F_{i}\right]^{1-\beta},
$$

where $\pi_{U_{i}}\left(w_{i}, w_{j}^{S T}\right)=\left(w_{i}-c\right) q_{i}\left(w_{i}, w_{j}^{S T}\right)$ and $\pi_{D_{i}}\left(w_{i}, w_{j}^{S T}\right)$ is obtained after substituting (4) into (2). Note that the disagreement payoffs for both the upstream and the downstream firms 
are equal to zero since none of the firms has an alternative trading partner. Maximizing (5) with respect to $F_{i}$, we get:

$$
F_{i}=\beta \pi_{D_{i}}\left(w_{i}, w_{j}^{S T}\right)-(1-\beta) \pi_{U_{i}}\left(w_{i}, w_{j}^{S T}\right)
$$

Using (6), the net profits of $U_{i}$ and $D_{i}$ can be rewritten as:

$$
\begin{aligned}
\pi_{U_{i}}\left(w_{i}, w_{j}^{S}\right)+F_{i} & =\beta\left[\pi_{U_{i}}\left(w_{i}, w_{j}^{S}\right)+\pi_{D_{i}}\left(w_{i}, w_{j}^{S}\right)\right] \\
\pi_{D_{i}}\left(w_{i}, w_{j}^{S}\right)-F_{i} & =(1-\beta)\left[\pi_{U_{i}}\left(w_{i}, w_{j}^{S}\right)+\pi_{D_{i}}\left(w_{i}, w_{j}^{S}\right)\right] .
\end{aligned}
$$

Substituting the above expressions into (5), we observe that the generalized Nash product reduces to an expression proportional to the joint profits of $U_{i}$ and $D_{i}$. Hence, $w_{i}$ is chosen to maximize these joint profits:

$$
\max _{w_{i}}\left[\pi_{U_{i}}\left(w_{i}, w_{j}^{S T}\right)+\pi_{D_{i}}\left(w_{i}, w_{j}^{S T}\right)\right]=\left[a-q_{i}\left(w_{i}, w_{j}^{S T}\right)-\gamma q_{j}\left(w_{i}, w_{j}^{S T}\right)-c\right] q_{i}\left(w_{i}, w_{j}^{S T}\right) .
$$

From the first order conditions of (8), we find the equilibrium wholesale prices:

$$
w^{S T}=w_{i}^{S T}=w_{j}^{S T}=c-\frac{\gamma^{2}(a-c)}{4+2 \gamma-\gamma^{2}} .
$$

Lemma 1 When firms bargain over two-part tariff contracts, the equilibrium wholesale price in the case of separate upstream firms is always lower than the upstream marginal cost, $w^{S T}<c$.

According to Lemma 1, the wholesale prices reflect a subsidy from the separate upstream firms to their respective downstream firms. This is a well-known result in the strategic delegation literature (see e.g. Vickers, 1985, Fershtman and Judd, 1987, and Sklivas, 1987). The intuition is as follows. A vertical chain, via a lower wholesale price, can commit to a more aggressive behavior in the final product market. The reaction curve of its downstream firm shifts out, and as the reaction curves are downward slopping, this results in lower quantity for the rival downstream firm, and higher quantity and gross profits for the own downstream firm. The portion of these gross profits that is transferred upstream, via the fixed fee, not only compensates for the upstream losses but also leaves a "good deal" of profits to the upstream firm. Clearly, this result is not valid in the case of wholesale price contracts (see Davidson, 1988, Horn and Wolinsky, 1988, as well as Appendix A). In other words, when firms bargain 
over wholesale price contracts, the wholesale price is the only available instrument - fixed fees are not available - and the equilibrium wholesale prices exceed the upstream marginal cost, $w^{S W}>0$.

Two additional remarks regarding the equilibrium wholesale prices (9) are in order. First, note that $\partial w^{S T} / \partial \gamma<0$, that is, the amount of the subsidy increases with the degree of substitutability. This is so because the closer substitutes the two goods are, the stronger is the downstream competition, and thus the more important is to be aggressive. Clearly, in the limit case where the final products are independent, there is no strategic role for subsidies and the equilibrium wholesale prices turn out to be equal to the marginal cost of the input $c$. Second, note that the equilibrium wholesale prices (9) are independent of the bargaining power distribution. This occurs because, as we saw above, $w_{i}$ is simply chosen in order to maximize the joint profits of $U_{i}$ and $D_{i}$. The sharing of these profits is done through $F_{i}$ and is according to the respective bargaining powers of the upstream and the downstream firms (see (7)).

\section{Bargaining over a Two-part Tariff Contract and a Wholesale Price Contract}

We turn now to the analysis of the subgame in which the two vertical chains trade using different contract types. In particular, $U_{i}$ and $D_{i}$ trade using a two-part tariff contract, while $U_{j}$ and $D_{j}$ trade using a wholesale price contract. ${ }^{11}$

$U_{i}$ and $D_{i}$, taking as given the outcome $\left(w_{j}^{S A}\right)$ of the simultaneously run negotiations between $U_{j}$ and $D_{j}$, choose $w_{i}$ and $F_{i}$ to maximize their Nash product, given by (5) from before with $w_{j}^{S T}=w_{j}^{S A}$. At the same time, $U_{j}$ and $D_{j}$, taking as given the outcome $\left(w_{i}^{S A}, F_{i}^{S A}\right)$ of the negotiations between $U_{i}$ and $D_{i}$, choose $w_{j}$ to maximize their Nash product, given by:

$$
\max _{w_{i}}\left[\pi_{U_{i}}\left(w_{i}, w_{j}^{S A}\right)\right]^{\beta}\left[\pi_{D_{i}}\left(w_{i}, w_{j}^{S A}\right)\right]^{1-\beta}
$$

From the first order conditions of (5) and (10), we obtain the equilibrium wholesale prices in the asymmetric contract types case:

$$
\begin{aligned}
w_{i}^{S A} & =c-\frac{(2-\gamma) \gamma^{2}(4+\beta \gamma)(a-c)}{32-16 \gamma^{2}+\beta \gamma^{4}} \\
w_{j}^{S A} & =c+\frac{\beta\left(16-8 \gamma-8 \gamma^{2}+2 \gamma^{3}+\gamma^{4}\right)(a-c)}{32-16 \gamma^{2}+\beta \gamma^{4}}
\end{aligned}
$$

\footnotetext{
${ }^{11}$ As mentioned above there is another subgame, the one in which $U_{i}$ and $D_{i}$ trade using a wholesale price, while $U_{j}$ and $D_{j}$ trade using a two-part tariff contract. The analysis for this subgame is symmetric to this one, and thus, we omit it.
} 
It is easy to see that $w_{i}^{S A}<c$ and $w_{j}^{S A}>c$. In other words, just like expected, the wholesale price in the chain that uses a wholesale price contract exceeds the marginal cost. The wholesale price instead in the chain that uses a two-part tariff contract is below the marginal cost, and thus, $D_{i}$ 's production is subsidized.

\section{- Upstream Horizontal Merger}

We turn now to the derivation of the bargaining outcomes in the case in which the two upstream suppliers are horizontally integrated. There are two possible third-stage subgames depending on whether the upstream monopolist bargains with its downstream customers over wholesale price or two-part tariff contracts. We analyze here in detail only the subgame in which bargaining is over two-part tariff contracts. The analysis for the subgame with wholesale price contracts can be found in Horn and Wolinsky (1988) as well as in Appendix A.

The upstream monopolist $U$ bargains with the downstream firm $D_{i}$ over both the wholesale price $w_{i}$ and the fixed fee $F_{i}$, taking as given the outcome of its simultaneously run negotiations with $D_{j}$. Letting $\left(w_{j}^{M T}, F_{j}^{M T}\right)$ denote the equilibrium outcome of the bargaining between $U$ and $D_{j}$, that is, the anticipated wholesale price and fixed fee to be paid by $D_{j}, w_{i}$ and $F_{i}$ are chosen to maximize the generalized Nash product:

$$
\max _{w_{i}, F_{i}}\left[\pi_{U}\left(w_{i}, w_{j}^{M T}\right)+F_{i}+F_{j}^{M T}-d\left(w_{j}^{M T}, F_{j}^{M T}\right)\right]^{\beta}\left[\pi_{D_{i}}\left(w_{i}, w_{j}^{M T}\right)-F_{i}\right]^{1-\beta}
$$

where it is important to note that the profits of the upstream firm arise now from sales to two instead of one downstream firms. In particular, $\pi_{U}\left(w_{i}, w_{j}^{M T}\right)=\left(w_{i}-c\right) q_{i}\left(w_{i}, w_{j}^{M T}\right)+$ $\left(w_{j}^{M T}-c\right) q_{j}\left(w_{i}, w_{j}^{M T}\right)$. It is also important to note that the upstream disagreement payoff is no longer null. $U$ has an 'outside option'. In particular, if an agreement between $U$ and $D_{i}$ is not reached, then $U^{\prime} s$ disagreement payoff is equal to $U$ 's profits when $D_{j}$ operates as a downstream monopolist facing a per unit of input cost equal to the equilibrium wholesale price anticipated to be established in the bargaining between $U$ and $D_{j}$. In other words, the disagreement payoff of $U$ is given by $d\left(w_{j}^{M T}, F_{j}^{M T}\right)=\left(w_{j}^{M T}-c\right) q_{j}^{m}\left(w_{j}^{M T}\right)+F_{j}^{M T}$, with $q_{j}^{m}\left(w_{j}^{M T}\right)=\left(a-w_{j}^{M T}\right) / 2$ denoting the quantity produced by $D_{j}$ when it acts as a monopolist facing input price $w_{j}^{M T}$. Maximizing (13), first with respect to $F_{i}$, we get:

$$
F_{i}=\beta \pi_{D_{i}}\left(w_{i}, w_{j}^{M T}\right)-(1-\beta)\left[\pi_{U}\left(w_{i}, w_{j}^{M T}\right)+F_{j}^{M T}-d(.)\right]
$$


Using (14), the expressions within the brackets of (13) can be rewritten as:

$$
\begin{aligned}
\pi_{U}\left(w_{i}, w_{j}^{M T}\right)+F_{i}+F_{j}^{M T}-d(.) & =\beta\left[\pi_{U}\left(w_{i}, w_{j}^{M T}\right)+F_{j}^{M T}+\pi_{D_{i}}\left(w_{i}, w_{j}^{M T}\right)-d(.)\right] ; \quad(15) \\
\pi_{D_{i}}\left(w_{i}, w_{j}^{M T}\right)-F_{i} & =(1-\beta)\left[\pi_{U}\left(w_{i}, w_{j}^{M T}\right)+F_{j}^{M T}+\pi_{D_{i}}\left(w_{i}, w_{j}^{M T}\right)-d(.)\right] .
\end{aligned}
$$

Substituting the above expressions into (13), it follows that the generalized Nash product reduces to an expression proportional to the 'extra' joint surplus generated by $U$ and $D_{i}$, that is, the sum of the profits of $U$ and $D_{i}$ minus $U$ 's disagreement payoff from dealing with $D_{j}$ alone. Hence, $w_{i}$ is chosen to maximize this extra joint surplus:

$$
\max _{w_{i}}\left[\pi_{U}\left(w_{i}, w_{j}^{M T}\right)+\pi_{D_{i}}\left(w_{i}, w_{j}^{M T}\right)+F_{j}^{M T}-d(.)\right] .
$$

From the first order conditions of (16), we obtain the equilibrium wholesale prices:

$$
w^{M}=w_{i}^{M}=w_{j}^{M}=c-\frac{\gamma^{2}(a-c)}{2\left(2-\gamma^{2}\right)} .
$$

Lemma 2 When firms bargain over two-part tariff contracts, the equilibrium wholesale price in the case of an upstream horizontal merger is always lower than the upstream marginal cost, $w^{M T}<c$.

Interestingly, the upstream monopolist is not able to exploit its monopoly power. That is, it cannot charge the wholesale prices that lead to monopoly profits. Instead of doing this, it actually ends up subsidizing its downstream customers. This is due to the fact that the monopolist faces a 'commitment problem' when it deals privately with competing downstream firms. The monopolist's 'commitment problem' that has been identified also by McAfee and Schwartz (1995) and Rey and Vergé (2004) corresponds to the inability of $U$ to commit to $D_{i}$ that it will not offer a lower wholesale price to $D_{j} .{ }^{12} D_{i}$ knows that $U$ has incentives to behave opportunistically and make $D_{j}$ an aggressive competitor in the final product market via a lower wholesale price $w_{j}$ because it can then use the fixed fee $F_{j}$ in order to transfer upstream the higher profits of $D_{j}$. Anticipating this, $D_{i}$ will never agree on a wholesale price

\footnotetext{
${ }^{12}$ The monopolist's commitment problem also arises in settings in which there is unobservability of the contract terms i.e. when the downstream firms do not observe the contract terms faced by their rival before competing in the downstream market. See e.g. O' Brien and Shaffer (1992), McAfee and Schwartz (1994), and Rey and Tirole (2006).
} 
that is not below the upstream marginal cost, $w_{i} \geq c{ }^{13}$

As it can been by (17), in the merger case too the subsidy decreases as the degree of substitutability of the final goods becomes smaller, $\partial w^{M T} / \partial \gamma<0$ and the equilibrium wholesale prices continue to be independent of the bargaining power distribution.

Comparing the equilibrium wholesale price in the case of an upstream merger (17) with the respective one in the case of separate suppliers (9), we obtain the following result.

Proposition 1 When firms bargain over two-part tariff contracts, the equilibrium wholesale price in the case of an upstream horizontal merger is always lower than in the case of separate upstream firms, $w^{M T}<w^{S T}$.

Surprisingly, the equilibrium wholesale price in the case of an upstream merger is lower than the wholesale price in the case of separate upstream suppliers. The intuition behind this result hinges on the fact that an increase in the wholesale price $w_{i}$ charged to $D_{i}$ leads to a decrease in the output of $D_{i}$ and to an increase in the output of the rival downstream firm $D_{j}$. We call this latter effect 'output effect'. Under two-part tariffs, the output effect is negative. This is so because the increase in $D_{j}$ 's output due to an increase in $w_{i}$ means also an increase in the subsidy to $D_{j}$ given that under two-part tariffs downstream production is subsidized $\left(w^{M T}<w^{S T}<c\right)$. Recall now that a only merged upstream firm sells to both downstream firms. That is, only a merged firm can internalize the output effect. Since the output effect is negative under two-part tariff contracts, it follows that the upstream incentives to increase the wholesale prices are weaker in the case of merger than in the case of separate upstream firms.

Horn and Wolinsky (1988) have demonstrated that exactly the opposite result holds under wholesale price contracts. That is, the impact of an upstream merger on the equilibrium wholesale prices is positive under linear contracts. This occurs because under wholesale price contracts, downstream production is not subsidized, and thus, the above mentioned output effect is positive instead of negative. Because the positive output effect is internalized only in the merger case, the wholesale prices are higher when the upstream firms merge than when they remain separated.

\footnotetext{
${ }^{13}$ Experimental evidence support the existence of the monopolist's commitment problem. In particular, Martin et al. (2001) have observed that an upstream supplier achieves the monopoly outcome significantly less often when it deals privately with its competing downstream customers.
} 


\section{Merger Incentives under Exogenous Contracts}

In this Section, we depart from our basic model and explore the merger incentives when the contract type is given instead of selected by the firms in the second stage of the game.

We start with the analysis of the upstream firms' merger decision when two-part tariff contracts are used.

Proposition 2 When firms bargain over two-part tariff contracts, the upstream firms have no incentives to merge horizontally.

One would expect that upstream profits would be higher in the case of merger because an upstream monopolist would enjoy a stronger bargaining position due to its outside options, that would allow him to extract a higher share of the total surplus. As stated in Proposition 2 , we find that this is not the case under two-part tariff contracts. That is, the merger has a negative, and not a positive, impact on the total upstream profits. This occurs, first, because the lower wholesale prices in the merger case relative to the wholesale prices in the no-merger case (Proposition 1) lead to fiercer competition, and thus, to a lower total surplus. And second, because the bargaining position of an upstream merged firm is not always stronger than that of independent upstream firm. This surprising result is due to the fact that the monopolist's 'variable disagreement payoff', that is, its profits in case of disagreement with $D_{i}$ gross from the fixed fee, is negative. ${ }^{14}$ Why is it negative? Because in case of disagreement with $D_{i}$, the production of the rival downstream firm $D_{j}$ that acts as a downstream monopolist is subsidized under two-part tariff contracts $\left(w^{M T}<c\right)$. The negative variable disagreement payoff, under certain conditions, offsets the positive fixed disagreement payoff, leading to a negative total disagreement payoff $d\left(w^{M T}, F^{M T}\right)$, and thus, to a weaker disagreement position for the merged firm. ${ }^{15}$ Now, even when the upstream merged firm enjoys a stronger bargaining position, that is, when the total disagreement payoff is positive, the higher share of the total surplus that the merged firm is able to extract corresponds to lower profits than the profits that correspond to a smaller share of a higher total surplus in the case of separate firms.

The above finding contrasts with the result of Horn and Wolinsky (1988) according to

\footnotetext{
${ }^{14}$ The term 'variable disagreement payoff' simply refers to the variable part of $U$ 's total disagreement payoff, i.e. the first term of $d\left(w_{j}^{M}, F_{j}^{M}\right)$.

${ }^{15}$ The fixed disagreement payoff, simply refes to the fixed fee, $F_{j}^{M}$, included in $U$ 's total disagreement payoff $d\left(w_{j}^{M}, F_{j}^{M}\right)$.
} 
which merger incentives are always present when the downstream firms produce substitute goods. The reversal of the result is simply due to the fact that, in contrast to the case of two-part tariff contracts, both the output effect and the merged firm's variable disagreement payoff are always positive under linear contracts.

Combining the result of Proposition 2 with the above mentioned result of Horn and Wolinsky (1988), we conclude that the contract type can have significant implications for the equilibrium industry structure. While under wholesale price contracts, upstream firms decide to merge, under two-part tariff contracts, they decide to remain separated. Clearly then our analysis leads to the following testable implication: In the absence of any efficiency gains, higher upstream concentration should be observed in industries where trading is conducted through linear contracts, than in industries where trading is conducted through non-linear contracts.

\section{$5 \quad$ Merger Incentives under Endogenous Contracts}

We examine now the upstream firms' incentives to merge when the contract type is endogenous. Recall that in accordance to the timing of our basic model, first, the upstream firms decide whether or not they will merger, and then, they choose the contract type. Moving backwards, we start with the analysis of their contract type decision both for the case of separate upstream firms and the case of an upstream horizontal merger. The next Lemma contains the result for the former case.

Lemma 3 A separate upstream firm $U_{i}, i=1,2$, always chooses a two-part tariff contract.

According to Lemma 3, when the upstream firms are separated, they prefer to trade with their downstream customers using two-part tariff contracts instead of wholesale price contracts. This result can also be found in Milliou et al. (2006). ${ }^{16}$ The rationale behind it hinges on two arguments. First, while two-part tariff contracts are conditionally efficient (i.e. they maximize the vertical chain's joint profits given the rival chain's strategy), wholesale price contracts are not. Second, while under two-part tariff contracts, the vertical chain's joint profits are shared according to the firms' bargaining powers, under wholesale price contracts the downstream

\footnotetext{
${ }^{16}$ Gal-Or (1991) and Rey and Stiglitz (1995) also obtain this result in settings though in which bargaining is absent and the downstream competition is in prices.
} 
firms enjoy a larger share than the one corresponding to their bargaining power. ${ }^{17}$ Since an upstream firm enjoys a greater share of a larger pie with a two-part tariff contract than with a wholesale price contract, it chooses to use the former.

Analyzing the contract choice decision in the case of an upstream horizontal merger, we find the following.

Lemma 4 When the final products are sufficiently close substitutes $(\gamma>0.806)$, an upstream monopolist always chooses a wholesale price contract. For lower degrees of product substitutability, there exists $\beta_{T}(\gamma)$, such that an upstream monopolist chooses a wholesale price contract if $\beta<\beta_{T}(\gamma)$ and a two-part tariff contract otherwise. Moreover, $\beta_{T}($.$) is increasing in \gamma$ and $\beta_{T}(0)=0$.

Interestingly, an upstream monopolist does not always prefer two-part tariff contracts over linear wholesale price contracts. Its contract type choice depends crucially on the distribution of bargaining power and the intensity of downstream competition. In particular, an upstream monopolist prefers to use two-part tariff contracts only if its bargaining power is sufficiently high and the final products are not very close substitutes i.e. to the left of the $\beta_{T}(\gamma)$ curve in Figure 1. In all other cases, the upstream merged firm prefers to use wholesale price contracts. The intuition of Lemma 4 is as follows. The input price under two-part tariff contracts is lower than the respective under wholesale price contracts, $w^{M T}<c<w^{M W}$. This implies that the downstream competition under two-part tariffs is stronger, and in turn, that the total surplus to be shared among the upstream monopolist and the downstream firms is smaller under twopart tariffs than under wholesale prices. It follows that when the goods are close substitutes, and thus downstream competition is strong, the monopolist's incentives to select two-part tariff contracts are reduced. While under two-part tariffs the merged firm receives the share of the joint surplus that corresponds to its bargaining power, (see (15)), it receives a lower portion of the surplus under wholesale price contracts. ${ }^{18}$ Thus, when the upstream bargaining power is high (high $\beta$ ), its incentives to use wholesale price contracts are reduced because under such contracts it will obtain a smaller share of the surplus than the one corresponding to its high bargaining power.

\footnotetext{
${ }^{17}$ A more detailed explanation can be found in Milliou et al. (2006).

${ }^{18}$ To see this last point one has first to rewrite the focs of $(21)$ as: $\frac{\pi_{U}-d}{\pi_{D_{i}}}=\frac{\beta}{1-\beta} \frac{\partial \pi_{U} / \partial w_{i}}{\left(-\partial \pi_{D_{i}} / \partial w_{i}\right)}$. Then, by the envelop theorem, $-\partial \pi_{D_{i}} / \partial w_{i}=q_{i}^{*}$, while $\partial \pi_{U} / \partial w_{i}=q_{i}^{*}+\left(w_{i}-c\right) \partial q_{i}^{*} / \partial w_{i}<q_{i}^{*}$, because $w_{i}>c$. Hence, $\frac{\pi_{U}-d}{\pi_{D_{i}}}<\frac{\beta}{1-\beta}$.
} 
In light of the impact of the market structure on contract choice, we turn to the beginning of the game, that is, we examine whether or not the upstream firms have incentives to integrate horizontally.

Proposition 3 When the final products are sufficiently close substitutes $(\gamma>0.975)$, the upstream firms always have incentives to merge horizontally. For lower degrees of product substitutability, there exists a $\beta_{M}(\gamma)$, such that the upstream firms have incentives to merge horizontally if and only if $\beta<\beta_{M}(\gamma)$. Moreover, $\beta_{M}(\gamma)<\beta_{T}(\gamma)$, with $\beta_{M}($.$) is increasing in$ $\gamma$ and $\beta_{M}(0)=0$.

Proposition 3 states that under endogenous contracts, merger incentives are present when the final products are almost homogeneous as well as when the upstream bargaining power is sufficiently low $\left(\beta<\beta_{M}(\gamma)\right)$ for lower degrees of product substitutability, i.e. to the right of the $\beta_{M}(\gamma)$ curve in Figure 1. Note that the $\beta_{M}(\gamma)$ curve lies to the left of the $\beta_{T}(\gamma)$ curve. As a consequence, when the merger takes place in equilibrium, the subsequent equilibrium contract type is the wholesale price contract $\left(\beta<\beta_{T}(\gamma)\right)$. Intuitively, when the upstream bargaining power is high $\left(\beta>\beta_{T}(\gamma)\right)$ the contract type used both by a merged upstream firm and by an independent one is the two-part tariff contract (Lemmata 3 and 4). Clearly then under two-part tariff contracts the upstream firms do not have incentives to merge (Proposition 3). When the upstream bargaining power is low instead $\left(\beta<\beta_{T}(\gamma)\right)$, a wholesale price contract will be used in the case of a merger and a two-part tariff contract in the case of separate suppliers (Lemmata 3 and 4). Choosing thus between merging and remaining separated the upstream firms are facing a trade off between the inefficiency from double marginalization (wholesale price contracts) and the inefficiency from below marginal cost pricing (two-part tariff contracts). When the upstream bargaining power is sufficiently low $\left(\beta<\beta_{M}(\gamma)\right)$, the inefficiency from double marginalization is stronger and thus the upstream firms decide to merge. For similar reasons, when the products are almost perfect substitutes $(\gamma>0.975)$, there are incentives for merger independently of how powerful upstream firms are.

It follows from the above that while under exogenous contract types, the merger decision is a clear-cut decision, under endogenous contracts, it depends both on the degree of downstream competition and the distribution of bargaining power. Thus, the predictions regarding the market structure under endogenous contracts differ from the respective ones under given contract types. A finding that suggests that the widely adopted assumption in the existing 
literature that the contract type is exogenously given cannot be innocuous.

\section{Welfare Implications}

In this Section, we examine the effects of an upstream horizontal merger on downstream profits, consumers' surplus and total welfare and discuss the policy implications of our findings.

Defining total welfare as the sum of consumers' surplus and upstream and downstream firms' profits, we obtain the following results.

Proposition 4 An upstream horizontal merger has a positive (negative) effect on downstream firms' profits, on consumers' surplus and on total welfare when firms bargain over two-part tariff (wholesale price) contracts.

In contrast to conventional wisdom, Proposition 4 asserts that downstream firms can be better off with a monopolized upstream market. This occurs when trading takes place through two-part tariff contracts and it is a straightforward implication of the more favorable terms of trade that downstream firms face when dealing with an upstream monopolist (Proposition 1).

Proposition 4 also asserts that under two-part tariff contracts, the consumers are better off too when the upstream firms merge. This is again an implication of the lower wholesale prices in the merger case that translate in turn into lower prices for the final goods.

Recall that according to Proposition 2, the merger has a negative effect on upstream profits under two-part tariff contracts. Yet, as stated in Proposition 4, the merger has a positive effect on total welfare under two-part tariff contracts. That is, its negative effect on upstream profits is dominated by its above mentioned positive effects on consumer surplus and downstream profits. It follows from this that a horizontal merger can be pro-competitive even if it does not lead to any efficiency gains for the merged firms.

Under wholesale price contracts we have the reversal of all the above results. That is, in accordance with Proposition 4, an upstream merger leads to a decrease both in downstream profits and consumers' surplus, as well as to a decrease in total welfare. The reversal of the results is simply due to the fact that the downstream firms face higher input prices when the merger takes place under wholesale price contracts, and in turn, the consumers face higher final prices. 
Recall that in our basic model, that is, under endogenous contracts, two market structures can arise in equilibrium. In one of them, the upstream firms are separated and trade using two-part tariff contracts and in the alternative structure the firms merge and use wholesale price contracts. Welfare comparison of these two market structures, leads to the following result.

Proposition 5 Welfare in the case of separate upstream firms under two-part tariff contracts always exceeds welfare in the case of an upstream horizontal merger under wholesale price contracts.

According to Proposition 5, welfare is higher when the upstream firms remain separated than when they merge, given that in the former case they use two-part tariff contracts while in the merger case they use wholesale price contracts. The main force behind this finding is that the input prices are much lower under two-part tariffs (below $c$ ) than under wholesale price contracts.

Combining our results regarding the merger incentives both under exogenous and endogenous contracts (Propositions 2 and 3) with our welfare comparisons (Propositions 4 and 5), we are able to make the following observation.

Remark 1 In the absence of any efficiency gains, the upstream firms merge when their merger is welfare detrimental.

As stated in the above Remark, we conclude that the merger takes place only when it is welfare decreasing. For instance, while under exogenous wholesale price contracts, the upstream firms decide to merge, welfare is higher if they remain separated. The opposite holds under exogenous two-part tariff contracts. Even if a merger would then be welfare improving, the firms do not choose to merge in the absence of important merger-related cost savings. Similarly, under endogenous contracts, when the firms decide to merge they choose to trade though linear contracts, while welfare is higher if the firms remain separated, in which case they choose to trade through two-part tariff contracts.

In terms of policy conclusions, the above analysis suggests that a merger which takes place in a setting similar to the one considered here should not be allowed, unless there are significant efficiency gains or unless the antitrust authorities can impose a remedy regarding the contract type that the firms should use after they merge. In a more general context, the above analysis 
indicates that the welfare implications of horizontal mergers that take place in vertically related industries can differ significantly under different vertical contractual arrangements. Thus, it points out that in their treatment of such mergers, the antitrust authorities should take into account a number of crucial features of vertical related industries such as the vertical trading arrangements used. Failing to do so, that is, focusing only an horizontal features, could lead to an imprecise account of the effects of horizontal mergers and thus possibly, to misleading policy recommendations.

\section{Sequential Bargaining and Market Foreclosure}

In our basic model, we have assumed that when the merger takes place, the newly formed upstream monopolist bargains simultaneously with its two downstream clients. Here, we relax this assumption and examine what happens instead when the upstream monopolist bargains sequentially with the downstream firms. Under this modification, we re-examine the merger incentives assuming, for simplicity reasons, that trading both in the case of separate firms and in the case of merger takes place through two-part tariff contracts. Doing so, we reassert that under some circumstances, there are no incentives for an upstream merger.

The twisting point of the analysis here is that under sequential bargaining, an upstream monopolist can credibly commit to foreclose one of the downstream firms. To see this, let the upstream monopolist $U$ bargain first with $D_{1}$ and then with $D_{2}$. The upstream monopolist has the option to bring the negotiations with $D_{1}$ to a "dead end" if it wishes to do so. In case it does so, that is, in case of disagreement with $D_{1}$, the upstream monopolist bargains over a two-part tariff with $D_{2}$. It is easy to see that in this case bargaining will lead to the maximization of their joint profits, which will then be divided according to their respective bargaining powers. In particular, $w_{2}^{f}=c, \pi_{D_{2}}^{f}=(1-\beta)(a-c)^{2} / 4$ and $\pi_{U}^{f}=\beta(a-c)^{2} / 4$. Therefore, under sequential bargaining, the upstream monopolist can foreclose $D_{1}$ and attain profits equal to $\pi_{U}^{f}{ }^{19}$ It will certainly choose to do so whenever the overall profits that the upstream monopolist expects from the sequence of successful negotiations with the two downstream firms are lower than $\pi_{U}^{f}$.

The following Proposition summarizes our main results under sequential bargaining.

\footnotetext{
${ }^{19}$ Under simultaneous bargaining, $U$ cannot credibly commit to bring the negotiations with, say $D_{1}$, into a "dead end", although it has a clear incentive to do so. In fact, $D_{2}$ knows that, once it agrees to a wholesale price $w_{2}^{f}=c$ (and makes its corresponding transfer upstream $F_{2}^{f}$ ), $U$ has an incentive to settle to a lower wholesale price with $D_{1}$ and increase thus its overall profits.
} 
Proposition 6 Under sequential bargaining over two-part tariff contracts, when the products are not close substitutes $(\gamma<0.702)$, there exists $\beta_{s}(\gamma)$ such that for all $\beta \geq \beta_{s}(\gamma)$, the upstream firms do not merge horizontally. Otherwise, the upstream firms merge horizontally and the upstream monopolist sells to both downstream firms for all $\gamma$ if $\beta<\beta_{s}(\gamma)$, while it forecloses one of the downstream firms for the rest of the parameter values. Moreover, $\beta_{s}($.$) is$ decreasing in $\gamma$, with $\beta_{s}(0)=1$ and $\beta_{s}(1)=0$.

Proposition 6 tells us that if the goods are not close substitutes and the upstream bargaining power is relatively high, the upstream firms prefer to act as independent suppliers under two part tariff contracts. It also tells us that when the goods are close substitutes, relatively powerful upstream firms have incentives to merge and via the sequential bargaining pattern, foreclose one of the downstream firms. Figure 2 illustrates Proposition 6 by dividing the ( $\beta$, $\gamma$ ) parameter space in the three respective regions.

Intuitively, when the final goods are close enough substitutes, the upstream suppliers wish to merge because the merger allows them to eliminate the fierce downstream competition through the foreclosure of one of the downstream firms. When instead the final goods are not too close substitutes, the upstream firms may still wish to merge when their bargaining power is not high enough. This is so because a merged upstream firm has a stronger bargaining position than an independent one due to its outside option while bargaining with each one of the downstream firms. On the other hand, when relatively powerful upstream firms do not face strong downstream competition $(\gamma<0.702)$, they prefer to act as separate suppliers. This is due to the fact that when the upstream monopolist conducts successful sequential negotiations with the downstream firms, equilibrium wholesale prices are above marginal cost of input. This results into double marginalization which reduces the size of the pie to be shared among the upstream monopolist and the downstream firms. This latter negative effect is stronger than the negative effect due to below marginal cost of input pricing in case that separate suppliers use two-part tariffs and downstream competition is not too strong.

It is worth stressing that, under sequential bargaining, two-part tariff contracts can alter not only the upstream but also the downstream market structure. In particular, if $\gamma \geq 0.702$ and $\beta>\beta_{s}(\gamma)$, then the downstream market transforms also into a monopoly since the upstream monopolist forecloses one of the downstream firms. 


\section{Conclusion}

We have analyzed the incentives for horizontal mergers in intermediate product markets, along with the welfare implications of such mergers. We have allowed for bargaining between the vertically related firms and for two different contractual arrangements, linear wholesale price contracts and non-linear two-part tariff contracts.

We have shown that, in the absence of any efficiency gains, the upstream firms have a disincentive to merge when they trade using two-part tariff contracts. This result contrasts with the well-known result of Horn and Wolinsky (1988), according to which the upstream firms always decide to merge when they sell their products to competing downstream firms and trade using linear wholesale price contracts. We have also demonstrated that when the contract type is endogenous, the presence of merger incentives depends on the distribution of the bargaining power and the level of downstream competition. This is so because the contract type chosen by a merged upstream firm depends in turn on its bargaining power and the degree of product substitutability. These findings clearly indicate that the contract types can have significant implications for the equilibrium industry structure.

The desirability of upstream horizontal mergers from a social viewpoint also depends critically on the contract types used. While upstream horizontal mergers are welfare enhancing under two-part tariff contracts, they are welfare detrimental under wholesale price contracts. Since as we mentioned above, upstream firms decide to merge only under wholesale price contracts, an immediate policy conclusion is that horizontal mergers should not be allowed unless they lead to significant cost savings or unless the antitrust authorities can impose the contract type that the merged firms will use. While this policy conclusion should be taken with caution due to the simplicity of the setting under consideration, the conclusion that some features of vertically related industries can be crucial for horizontal mergers that take place in intermediate product markets seems to be more general. This last conclusion suggests that in the treatment of such mergers, the antitrust authorities should be taking into account, among

other things, important features of vertically related industries such as the vertical trading arrangements used. 


\section{Appendix A}

Separate Upstream Firms and Wholesale Price Contracts: Letting $w_{j}^{S W}$ denote the equilibrium outcome of the bargaining between $U_{j}$ and $D_{j}, w_{i}$ is chosen to maximize the generalized Nash bargaining product:

$$
\begin{aligned}
& \max _{w_{i}}\left[\pi_{U_{i}}\left(w_{i}, w_{j}^{S W}\right)\right]^{\beta}\left[\pi_{D_{i}}\left(w_{i}, w_{j}^{S W}\right)\right]^{1-\beta} \\
= & {\left[\left(w_{i}-c\right) \frac{a(2-\gamma)-2 w_{i}+\gamma w_{j}^{S W}}{4-\gamma^{2}}\right]^{\beta}\left[\frac{\left[a(2-\gamma)-2 w_{i}+\gamma w_{j}^{S W}\right]^{2}}{\left(4-\gamma^{2}\right)^{2}}\right]^{1-\beta} . }
\end{aligned}
$$

Taking the first order condition of (18), we obtain the equilibrium wholesale prices:

$$
w^{S W}=w_{i}^{S W}=w_{j}^{S W}=c+\frac{\beta(2-\gamma)(a-c)}{4-\beta \gamma}>c .
$$

Finally, substituting (19), we obtain the equilibrium downstream and upstream profits under wholesale price contracts:

$$
\pi_{D_{i}}^{S W}=\frac{4(2-\beta)^{2}(a-c)^{2}}{(2+\gamma)^{2}(4-\beta \gamma)^{2}} \quad \text { and } \quad \pi_{U_{i}}^{S W}=\frac{2 \beta(2-\beta)(2-\gamma)(a-c)^{2}}{(2+\gamma)(4-\beta \gamma)^{2}}
$$

Upstream Horizontal Merger and Wholesale Price Contracts: Letting $w_{j}^{M W}$ denote the equilibrium outcome of the bargaining between $U$ and $D_{j}$, that is, the anticipated wholesale price to be paid by $D_{j}, w_{i}$ is chosen to maximize the generalized Nash product:

$$
\begin{aligned}
& \max _{w_{i}}\left[\pi_{U}\left(w_{i}, w_{j}^{M W}\right)-d\left(w_{j}^{M W}\right)\right]^{\beta}\left[\pi_{D_{i}}\left(w_{i}, w_{j}^{M W}\right)\right]^{1-\beta} \\
= & {\left[\left(w_{i}-c\right) \frac{a(2-\gamma)-2 w_{i}+\gamma w_{j}^{M W}}{4-\gamma^{2}}-d\left(w_{j}^{M W}\right)\right]^{\beta}\left[\frac{\left[a(2-\gamma)-2 w_{i}+\gamma w_{j}^{S W}\right]^{2}}{\left(4-\gamma^{2}\right)^{2}}\right]^{1-\beta} }
\end{aligned}
$$

where $d\left(w_{j}^{M W}\right)=\left(w_{j}^{M W}-c\right) q_{j}^{m}\left(w_{j}^{M W}\right)$, with $q_{j}^{m}\left(w_{j}^{M W}\right)=\left(a-w_{j}^{M W}\right) / 2$, is the disagreement payoff of $U$, in case that $D_{j}$ acts as downstream monopolist in the final good market facing input price $w_{j}^{M W}$. Taking the first order conditions of (21) we obtain the equilibrium wholesale 
prices and the respective net equilibrium profits:

$$
\begin{gathered}
w^{M W}=w_{i}^{M W}=w_{j}^{M W}=c+\frac{\beta(a-c)}{2}>c \\
\pi_{D_{i}}^{M W}=\frac{(2-\beta)^{2}(a-c)^{2}}{4(2+\gamma)^{2}} \quad \text { and } \quad \pi_{U}^{M W}=\frac{\beta(2-\beta)(a-c)^{2}}{2(2+\gamma)} .
\end{gathered}
$$

\section{Appendix B}

Proof of Proposition 2: The net equilibrium profits of the upstream firms in the case of separate suppliers can be obtained after substituting (9) into (7):

$$
\pi_{U_{i}}^{S T}=\frac{2 \beta\left(2-\gamma^{2}\right)(a-c)^{2}}{\left(4+2 \gamma-\gamma^{2}\right)^{2}}
$$

The respective net equilibrium profits in the merger case are obtained after substituting (17) into (15):

$$
\pi_{U}^{M T}=\frac{(2-\gamma)\left[\beta\left(4-2 \gamma-2 \gamma^{2}+\gamma^{3}\right)-\gamma^{3}\right](a-c)^{2}}{4\left(2-\gamma^{2}\right)^{2}} .
$$

Note that under Assumption 1, $\pi_{U}^{M T}>0$. The result follows immediately after taking the difference $\pi_{U}^{M T}-\left(\pi_{U_{1}}^{S T}+\pi_{U_{2}}^{S T}\right)$ and noting that it is always negative.

Proof of Lemma 3: We already know from (20) and (25) the profits of an independent upstream firm in the case that both vertical chains use wholesale price contracts and in the case that they use two-part tariff contracts. It remains to determine the upstream profits for the case in which one of the vertical chains uses a two-part tariff contract while the other uses a wholesale price contract, and then check whether an upstream firm has incentives to deviate by switching to the other type of contract. Substituting (12) and (11) in the respective profits functions, we obtain:

$$
\begin{aligned}
\pi_{U_{i}}^{S A} & =\frac{2 \beta(2-\beta)\left(4-2 \gamma-\gamma^{2}\right)\left(16-8 \gamma-8 \gamma^{2}+2 \gamma^{3}+\gamma^{4}\right)(a-c)^{2}}{\left(32-16 \gamma^{2}+\beta \gamma^{4}\right)^{2}} \\
\pi_{U_{j}}^{S A} & =\frac{2 \beta(2-\gamma)^{2}\left(2-\gamma^{2}\right)(4+\beta \gamma)^{2}(a-c)^{2}}{\left(32-16 \gamma^{2}+\beta \gamma^{4}\right)^{2}}
\end{aligned}
$$

One can easily check that $\pi_{U_{j}}^{S A}<\pi_{U_{i}}^{S W}$. Hence, when $U_{i}$ uses a two-part tariff contract, $U_{j}$ has no incentive to switch from a two-part tariff to a wholesale price contract. Moreover, one can 
easily check that $\pi_{U_{i}}^{S A}>\pi_{U_{i}}^{S W}$. Hence, when $U_{j}$ uses a wholesale price contract, $U_{i}$ has always incentive to switch from a wholesale price to a two-part tariff contract. Evoking symmetry, the above arguments prove that a two-part tariff contract strictly dominates a wholesale price contract from the point of view of an upstream firm. Thus, an independent upstream firm will always choose a two-part tariff contract.

Proof of Lemma 4: This is an immediate consequence of the comparison of a merged upstream firm's profits in the case that it uses a wholesale price contract (24) and in the case it uses a two-part tariff contract (27). It turns out that $\pi_{U}^{M W}>\pi_{U}^{M T}$ if and only if $\beta<\beta_{T}(\gamma)=\frac{\gamma\left(4-\gamma^{2}\right)}{2\left(2-\gamma^{2}\right)}$. It is easy to check that $\beta_{T}(0)=0, d \beta_{T} / d \gamma>0$ and $\beta_{T}(\gamma)=1$ when $\gamma=0.806$.

Proof of Proposition 3: From Proposition 2 we know that, under two-part tariffs, a merged upstream firm obtains lower profits than the sum of the profits of the independent suppliers. Hence, for all parameter values for which a merged upstream firm prefers a two-part tariff contract (i.e. for all $\beta>\beta_{T}(\gamma)$ ), the upstream firms are better off by staying independent.

For the rest of the parameter values, in which the merged upstream firm prefers a wholesaleprice contract, one can check from (24) and (25) that $\pi_{U}^{M T}>\widehat{\pi}_{U_{1}}^{S T}+\widehat{\pi}_{U_{2}}^{S T}$ if and only if $\beta<$ $\beta_{M}(\gamma)=\frac{2 \gamma\left(8+4 \gamma+\gamma^{3}\right)}{\left(4+2 \gamma-\gamma^{2}\right)^{2}}$. Since $\beta_{M}(0)=0, d \beta_{M} / d \gamma>0, \beta_{M}(\gamma)=1$ for $\gamma=0.975$, and $\beta_{M}(\gamma)<$ $\beta_{T}(\gamma)$ for all $\gamma$, the result follows because by Lemma 3 the independent upstream firms always use two-part tariff contracts.

Proof of Proposition 4: Under wholesale price contracts, we obtain the result regarding the downstream profits from (24) and (20), by taking the difference of the sum of each downstream firm's profits in the case of a merger $\pi_{D}^{M W}=\pi_{D_{1}}^{M W}+\pi_{D_{2}}^{M W}$ and the respective sum in the case of independent upstream firms $\pi_{D}^{S W}=\pi_{D_{1}}^{S W}+\pi_{D_{2}}^{S W}$. Regarding the consumers' surplus result, we first calculate the consumers' surplus both in the case of a merger and in the case of independent suppliers:

$$
C S^{k}=\frac{1}{2}\left[q_{1}\left(w^{k}\right)^{2}+q_{2}\left(w^{k}\right)^{2}+2 \gamma q_{1}\left(w^{k}\right) q_{2}\left(w^{k}\right)\right], k=M W, S W
$$

Then we take their difference and our result follows. Regarding the total welfare result, we first calculate total welfare for both cases:

$$
W^{M W}=C S^{M W}+\pi_{D}^{M W}+\pi_{U}^{M W} \quad \text { and } \quad W^{S W}=C S^{S W}+\pi_{D}^{S W}+\pi_{U_{1}}^{S W}+\pi_{U_{2}}^{S W}
$$


And then taking their difference we see that $W^{M W}<W^{S W}$.

Under two-part tariffs, we obtain our results following the same steps as under wholesale price contracts above.

Proof of Proposition 5: We follow a similar procedure as the one in the proof of Proposition 4.

Proof of Proposition 6: Let $U$ bargain with $D_{1}$ in stage one and with $D_{2}$ in stage two. The final market competition stage, stage three, is the same as in Section 3.

In stage two, $U$ and $D_{2}$ bargain over $\left(w_{2}, F_{2}\right)$, given the outcome of the previous stage negotiations between $U$ and $D_{1}$. Assume for the moment that $U$ and $D_{1}$ have reached an agreement $\left(w_{1}, F_{1}\right)$. Then $U$ 's disagreement payoff is equal to $d\left(w_{1}, F_{1}\right)=\left(w_{1}-c\right) q_{1}^{m}\left(w_{1}\right)+F_{1}$, where $q_{1}^{m}\left(w_{1}\right)=\left(a-w_{1}\right) / 2$ is $D_{1}$ 's output when $D_{1}$ is a monopolist in the final market. The disagreement payoff of $D_{2}$ is zero. Now, maximization of the generalized Nash product first w.r.t. $F_{2}$ leads to a reduced problem where $U$ and $D_{2}$ choose $w_{2}$ to maximize their extra joint surplus:

$$
\begin{aligned}
& \max _{w_{2}}\left[\pi_{U}\left(w_{1}, w_{2}\right)+\pi_{D_{2}}\left(w_{1}, w_{2}\right)+F_{1}-d(.)\right]= \\
& {\left[a-q_{2}\left(w_{1}, w_{2}\right)-\gamma q_{1}\left(w_{1}, w_{2}\right)-c\right] q_{2}\left(w_{1}, w_{2}\right)+\left(w_{1}-c\right) q_{1}\left(w_{1}, w_{2}\right)-\left(w_{1}-c\right) q_{1}^{m}\left(w_{1}\right) .}
\end{aligned}
$$

From the first order conditions of (29), we obtain the wholesale price reaction function of $(U$, $\left.D_{2}\right)$ :

$$
w_{2}\left(w_{1}\right)=\frac{c(2+\gamma)\left(2-\gamma^{2}\right)^{2}-\gamma\left[a(2-\gamma) \gamma-2\left(2-\gamma^{2}\right) w_{1}\right]}{4\left(2-\gamma^{2}\right)} .
$$

Note that $\partial w_{2} / \partial w_{1}>0$, i.e. an increase in the wholesale price paid by $D_{1}$ makes now less profitable for $\left(U, D_{2}\right)$ to reduce the wholesale price paid by $D_{2}$.

In stage one, $U$ and $D_{1}$ bargain over $\left(w_{1}, F_{1}\right)$ taking into account how $\left(U, D_{2}\right)$ will react in the next stage. The disagreement payoff for $D_{1}$ is zero. In order to determine the disagreement payoff of $U$, we have to understand the continuation of the game in case of disagreement. In the latter market foreclosure case, $U$ and $D_{2}$ will bargain over a two-part tariff $\left(w_{2}^{f}, F_{2}^{f}\right)$ in the next stage. It is easy to see that, since disagreement payoffs for both parties will be zero, $U$ and $D_{2}$ will agree on $w_{2}^{f}=c$ in order to maximize their joint profits and that, the agreed fixed-fee $F_{2}^{f}$ will be such that the maximal joint profits will be shared among $U$ and $D_{2}$ according to their respective bargaining powers; therefore, $\bar{d}=\beta(a-c)^{2} / 4$. Taking this into account, the 
maximization of the generalized Nash product first w.r.t. $F_{1}$ leads to the reduced problem where $U$ and $D_{1}$ choose $w_{1}$ to maximize their extra joint surplus:

$$
\begin{aligned}
& \max _{w_{1}}\left[\pi_{U}\left(w_{1}, w_{2}\left(w_{1}\right)+\pi_{D_{1}}\left(w_{1}, w_{2}\left(w_{1}\right)\right)-\bar{d}\right]=-\bar{d}+\left(w_{2}\left(w_{1}\right)-c\right) q_{2}\left(w_{1}, w_{2}\left(w_{1}\right)\right)\right. \\
& +\left[a-q_{1}\left(w_{1}, w_{2}\left(w_{1}\right)\right)-\gamma q_{2}\left(w_{1}, w_{2}\left(w_{1}\right)-c\right] q_{1}\left(w_{1}, w_{2}\left(w_{1}\right)\right) .\right.
\end{aligned}
$$

where $w_{2}\left(w_{1}\right)$ is given by (30). Taking the first order conditions of (33) and using (30), we obtain the equilibrium wholesale prices

$$
w_{1}^{M}=c+\frac{(a-c) \gamma(2-\gamma)}{2\left(2-\gamma^{2}\right)} ; w_{2}^{M}=c
$$

Note that $w_{1}^{M}>w_{2}^{M}=c$. In contrast to the case of merged suppliers under simultaneous bargaining, the upstream monopolist does not subsidize downstream firms in the sequential bargaining case.

However, (32) is the solution to (33) only if the extra joint surplus - to be shared among $U$ and $D_{1}$ according to their respective bargaining powers - is positive. It can be checked that the extra joint surplus is positive only if $\beta \leq \beta_{s}(\gamma)=2(1-\gamma) /\left(2-\gamma^{2}\right)$. Moreover, for this range of parameters, the net equilibrium profits of the downstream and upstream firms turn out to be:

$$
\begin{aligned}
\pi_{D_{1}}^{M} & =\frac{(1-\beta)\left[2-2 \gamma-\beta\left(2-\gamma^{2}\right)\right](a-c)^{2}}{4\left(2-\gamma^{2}\right)} ; \pi_{D_{2}}^{M}=\frac{(1-\beta)(2-\gamma)^{2}(a-c)^{2}}{8\left(2-\gamma^{2}\right)} \\
\pi_{U}^{M} & =\frac{\left[(2-\gamma)^{2} \gamma^{2}-2 \beta^{2}\left(2-\gamma^{2}\right)^{2}+\beta\left(24-16 \gamma-14 \gamma^{2}+8 \gamma^{3}+\gamma^{4}\right)\right](a-c)^{2}}{8\left(2-\gamma^{2}\right)^{2}}
\end{aligned}
$$

Note that $\pi_{D_{1}}^{M}<\pi_{D_{2}}^{M}$, i.e. there is a last mover advantage for the downstream firms under two-part tariff contracts whenever the suppliers are merged.

If instead $\beta>\beta_{s}(\gamma), U$ has an incentive to bring its negotiations with $D_{1}$ to a dead end. Then under market foreclosure, the solution to the problem is, $w_{2}^{f}=c, \pi_{D_{1}}^{f}=0$, $\pi_{D_{2}}^{f}=(1-\beta)(a-c)^{2} / 4$, and $\pi_{U}^{f}=\beta(a-c)^{2} / 4$.

To complete the proof, we have to compare the aggregate profits of the independent suppliers with those of the upstream monopolist. If $\beta \leq \beta_{s}(\gamma)$, one can check from (25) and (34) that $\pi_{U_{1}}^{S T}+\pi_{U_{2}}^{S T}<\pi_{U}^{M}$. Hence, an upstream merger will occur in this range of parameters. 
If $\beta>\beta_{s}(\gamma)$, then $\pi_{U_{1}}^{S}+\pi_{U_{2}}^{S}<\pi_{U}^{f}$ only if $\gamma>0.702$. Otherwise, the inequality is reversed. Hence, an upstream merger with market foreclosure will occur if $\gamma>.702$ and $\beta>\beta_{s}(\gamma)$. Otherwise, the upstream firms will remain independent.

\section{References}

Cremer, J. and M. H. Riordan (1987), "On Governing Multilateral Transactions with Bilateral Contracts," Rand Journal of Economics, 18, 436-451.

Davidson, C. (1988), "Multiunit Bargaining in Oligopolistic Industries," Journal of Labor Economics, 6, 397-422.

Dobson, P. and M. Waterson (1997), "Countervailing Power and Consumer Prices," Economic Journal, 107, 418-430.

Fershtman C. and K. Judd (1987), "Equilibrium Incentives in Oligopoly," American Economic Review, 77, 927-940.

Gal-Or, E. (1991), "Duopolistic Vertical Restraints," European Economic Review, 34, 12371253.

Hart, O. and J. Tirole (1990), "Vertical Integration and Market Foreclosure," Brookings Papers on Economic Activity, Microeconomics, 205-276.

Horn, H. and A. Wolinsky (1988), "Bilateral Monopolies and Incentives for Merger," Rand Journal of Economics, 19, 408-419.

Inderst, R. and C. Wey (2003), "Bargaining, Mergers, and Technology Choice in Bilaterally Oligopolistic Industries," Rand Journal of Economics, 34, 1-19.

Lommerud, K. E., O. R. Straume and L. Sorgard (2005), "Downstream Merger with Upstream Market Power," European Economic Review, 49, 717-743.

Marshall, R. and A. Merlo (2004), "Pattern Bargaining," International Economic Review, 45, 239-255. 
McAfee, P. and M. Schwartz (1994), "Opportunism in Multilateral Vertical Contracting: Nondiscrimination, Exclusivity, and Uniformity," American Economic Review, 84, 210230.

McAfee, P. and M. Schwartz (1995), "The Non-Existence of Pairwise-Proof Equilibrium," Economics Letters, 49, 251-259.

Martin, S., H.-T. Normann and C. M. Snyder (2001), "Vertical Foreclosure in Experimental Markets," Rand Journal of Economics, 32, 466-496.

Milliou, C., E. Petrakis and N. Vettas (2006), "(In)efficient Trading Forms in Competing Vertical Chains," unpublished manuscript, Universidad Carlos III de Madrid.

O’Brien, D. and G. Shaffer (1992), "Vertical Control with Bilateral Contracts," Rand Journal of Economics, 23, 299-308.

O'Brien, D. and G. Shaffer (2005), "Bargaining, Bundling, and Clout: the Portfolio Effects of Horizontal Mergers," Rand Journal of Economics, 36, 573-595.

Rey, P. and J. Stiglitz (1995), "The Role of Exclusive Territories in Producers' Competition," Rand Journal of Economics, 26, 431-451.

Rey, P. and J. Tirole (2006), "A Primer on Foreclosure," in M. Armstrong and R. Porter (eds.), Handbook of Industrial Organization, Vol. 3, North-Holland, Amsterdam.

Rey, P. and T. Vergé (2004), "Bilateral Control with Vertical Contracts," Rand Journal of Economics, 35, 728-746.

Sklivas, S. D. (1987), "The Strategic Choice of Managerial Incentives," Rand Journal of Economics, 18, 452-458.

Symeonidis, G. (2005), "Collusion, Bargaining and Welfare," unpublished manuscript, University of Essex.

Vickers, J. (1985), "Delegation and the Theory of the Firm," Economic Journal, 95, 138-147.

von Ungern-Sternberg, T. (1996), "Countervailing Power Revisited," International Journal of Industrial Organization, 14, 507-519. 
Ziss, S. (1995), "Vertical Separation and Horizontal Mergers," Journal of Industrial Economics, 43, 63-75.

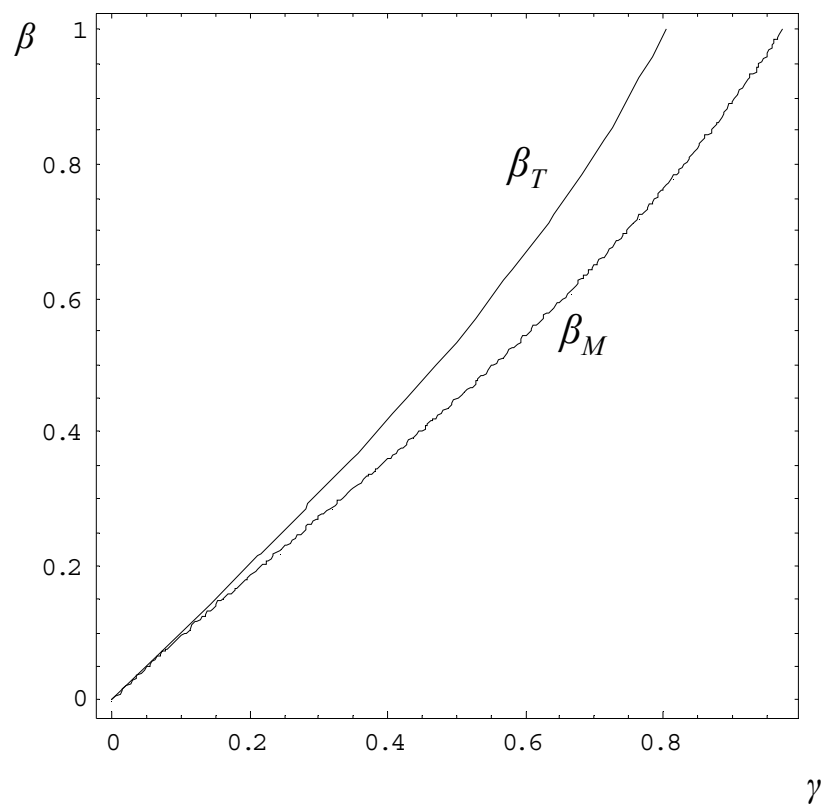

Figure 1: Endogenous Contracts and Merger Decision

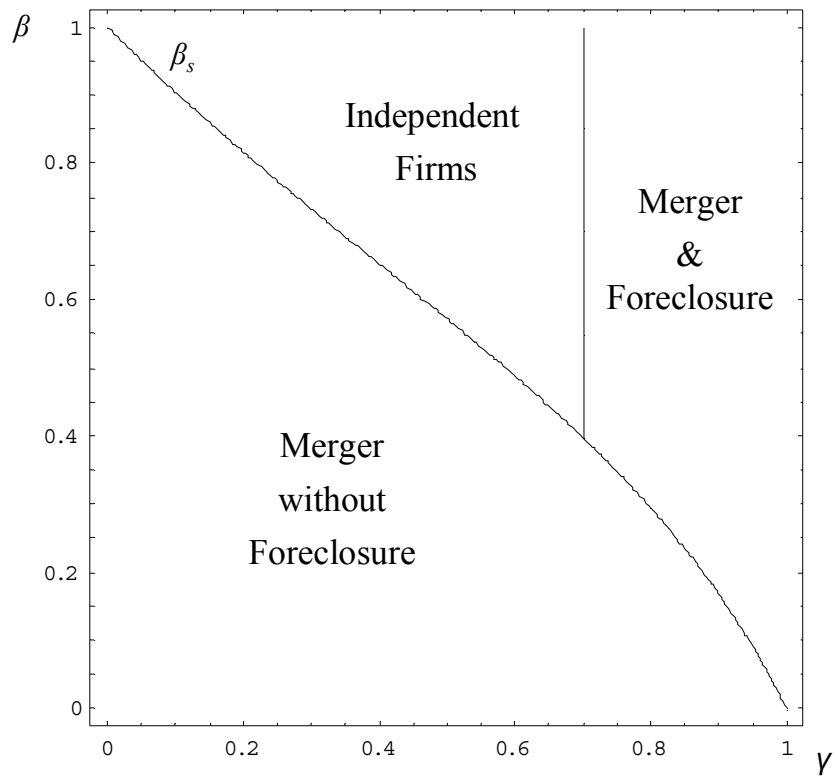

Figure 2: Sequential Bargaining and Merger Decision 